\title{
Cooperative Experiential Learning in a Flipped Translation Classroom
}

\author{
Yi-Ti $\operatorname{Lin}^{1}$ \\ ${ }^{1}$ Department of English, Tamkang University, New Taipei City, Taiwan \\ Correspondence: Yi-Ti Lin, Department of English, Tamkang University, 151 Yingzhuan Road, Tamsui Dist., \\ New Taipei City, 25137, Taiwan. E-mail: ytlin@mail.tku.edu.tw
}

Received: June 10, 2019 Accepted: July 3, 2019 Online Published: July 18, 2019

doi:10.5539/ijel.v9n5p29 URL: https://doi.org/10.5539/ijel.v9n5p29

\begin{abstract}
This research aims to investigate the perception of English as a Foreign Language (EFL) learners on cooperative experiential learning in a flipped translation classroom. Translation competence is seen as one of the essential language skills to acquire for English. In order to facilitate learners in developing translation skills, a learner-centered instruction integrating cooperative learning with experiential learning was implemented. A total of 13 English majors taking a required translation course at a university in Taiwan participated in the research. Data were collected from semi-structured interviews and analyzed systematically using a qualitative conductive approach. Results showed that the participants encountered different obstacles when translating from English to Chinese and vice versa. The findings indicated that this flipped translation classroom enables learners to actively engage in the translation process and elevate the learning process from lower order thinking to higher order thinking. Pedagogical implications are suggested and research implications are also provided for future studies.
\end{abstract}

Keywords: translation, experiential learning model, cooperative learning, flipped classroom

\section{Introduction}

Translation competence is an important indicator of an individual's first and second language competences. To make translation learning more effective and efficient, we propose to have a learner-centered environment by integrating cooperative learning with the experiential learning model and have learners actively engaged in the learning process in a flipped translation classroom (Tucker, 2012; Bishop \& Verleger, 2013). Since learning is most effective when active engagement and higher order thinking take place (Bloom, Englehart, Furst, Hill, \& Krathwohl, 1956; Anderson \& Krathwohl, 2001), it would be better to make good use of class time and carry out activities that require higher order thinking. In this case, learners will undergo higher order thinking, such as discussing, analyzing, and recreating translations inside the classroom, and lower order thinking activities like understanding translation techniques and strategies, and applying those techniques when practicing translation outside of the classroom (Lage, Platt, \& Treglia, 2000). The purpose of a flipped translation instruction is different from a traditional translation classroom where the majority of class time is spent on lecturing translation techniques and practicing translation tasks. The goal of a cooperative experiential learning translation classroom is for leaners to develop autonomy in learning translation and to use higher order thinking to enhance their translation competence.

The cultivation of translation competence, like any other type of learning, is better looked at from a process-oriented perspective, in which the experiential learning model (Kolb, 2015) adequately explains the translation process. Experiential learning model is a repeated cycle of concrete experience, reflective observation, abstract conceptualization, and active experimentation. From the perspective of translation, concrete experience is the action of doing translation tasks at home. Reflective observation is doing the analysis and discussion in the classroom. Abstract conceptualization is the internalizing of new knowledge from previous analysis and discussion. Active experimentation is recreating and revising the translation. By integrating cooperative learning in stage two - reflective observation of the experiential learning model, learners can discuss and analyze translation samples with their classmates and form better judgments about their peers' and their own translations. The iterative process reinforces leaners' translation skills by actual doing, reflecting, internalizing, and practicing repeatedly to enhance their translation competence. Cooperative learning fits the experiential learning model perfectly, and thus, cooperative experiential learning model seems appropriate for a flipped translation classroom. 


\section{Literature Review}

\subsection{Flipped Classroom Instruction in Translation Training}

Based on constructivism, a learner-centered learning environment which promotes active learning would greatly enhance learning performance. Hence, a flipped classroom, which is learner-centered, is practical for meaningful learning to take place in the classroom (King, 1993; Roehl, Reddy, \& Shannon, 2013). Flipped classroom aims to invert classroom instruction by replacing lower order thinking with higher order thinking inside the classroom (Lage et al., 2000). Even though there is not a consensus on the definition of a flipped classroom, in general, a flipped classroom involves technology use outside of the classroom for presenting basic information, and interactive learning activities to take place inside the classroom (Tucker, 2012; Bishop \& Verleger, 2013). In accordance to the design of this study, we will adopt Bishop and Verleger's (2013) working definition which states that a flipped classroom involves computer-mediated instruction to take place outside the classroom before interactive learning activities to be held inside the classroom.

Effective learning is when learners take the responsibility of learning into their own hands, participate actively in the learning process, and internalize new knowledge to become part of their competence (Dewey, 1938; Prince, 2004; Zhong, 2008). Engaging learners in the learning actively is for them to do the activities and to think about what they are doing instead of sitting in the classroom and listening to lectures passively. Activities such as group discussion, team work cooperation, and problem-based tasks are considered part of active learning and have proven to be effective in facilitating learning performance. Therefore, it would be better to utilize classroom time effectively by devoting the effort to carry out activities that Bloom et al. (1956) referred to as higher order thinking like analyzing, evaluating, and creating new knowledge (Prince, 2004; Bergmann \& Sams, 2012; Berrett, 2012; Tucker, 2012; Hung, 2015), instead of lower order activities that involve remembering, understanding and applying.

Higher order thinking skills are considered important factors in language learning and also applicable in translation training (Shreve, 2006). At first, Bloom and his associates developed Bloom's Taxonomy for cognitive domains of learning on a continuum from lower order thinking skills to higher order thinking skills (Bloom et al., 1956). Later, Anderson and Krathwohl (2001) made revisions and presented Bloom's Revised Taxonomy to go from lower order thinking skills to higher order thinking skills in the order of remembering, understanding, applying, analyzing, evaluating, and creating. In a traditional translation classroom, lectures on translation techniques and strategies are usually introduced in the classroom. Lecturing involves lower order thinking like remembering, understanding, and perhaps applying. For higher order thinking to take place in a flipped translation classroom, tasks that require analyzing, evaluating, and creating should be carefully designed.

With many facets of learning translation, Shreve (2006) proposed that metacognition and deliberate practice are keys to translation expertise. Metacognition involves higher order thinking and active control during the cognitive process in translation. Also, deliberate practice using translation tasks of appropriate difficulty, informative feedback, followed by repetition and correction are critical factors in improving translation performance. Therefore, to help learners become actively engaged in learning translation, we designed a flipped translation classroom by integrating cooperative learning in the experiential learning model in the hopes of helping learners construct their translation competence.

\subsection{Cooperative Experiential Learning in Translation}

Emphasizing on the process of learning as opposed to the outcome, Kolb (2015) proposed the experiential learning model based on Dewey, Lewin, Vygotsky, and Piaget's theories claiming that knowledge is acquired and created through the transformation of experience. Deeply rooted in constructivism, the cyclical process of experiential learning repeats concrete experience, reflective observation, abstract conceptualization, and active experimentation, and enables the learners to transform the experience, and construct and internalize new knowledge which eventually leads to effective learning.

According to the experiential learning model, learners can begin by doing the translations on their own (i.e., a hands-on concrete experience). Then, incorporating cooperative learning, they can compare, discuss, and analyze the translations done by their peers, and then, reflect on their previous translations (i.e., reflective observation). After reflection, they can develop a better grasp of language usages and internalize new knowledge (i.e., abstract conceptualization). Finally, they can apply what they have learned when doing similar or new translations in the future (i.e., active experimentation) (Davies, 2005; Shreve, 2006; Calvo, 2015; Motta, 2016). Overall, the experiential learning model effectively explains the learning process of translation.

Since experiential learning has proven to be an effective approach to teaching and learning, it may be applicable 
in translation teaching in an EFL context. A learner-centered approach to teaching translation based on constructivism has been deemed effective (Kohonen, 1992; Kiraly, 1995, 2000; Colina, 2002). Previous findings support the notions of experiential learning which involve autonomous learning, pertaining to learners assuming responsibility for their own learning, developing awareness of the learning process, cooperating with their peers, and constructing and acquiring knowledge in the process (Davies, 2005; Shreve, 2006; Liao, 2009; Kiraly, 2014). Like language learning, learning to translate would be more effective from a process-oriented perspective deriving from a learner-centered approach and adopting the experiential learning model.

Therefore, based on the theoretical framework of cooperative learning, the experiential learning model, and flipped classroom, a flipped translation instruction is designed and learners' perception on a flipped translation classroom based on cooperative experiential learning model is the focus of investigation. This research aims to contribute to the still limited literature on translation instruction by providing an innovative way of teaching translation. We propose to investigate the effectiveness of cooperative experiential learning model in a flipped translation classroom and the following research questions are asked. First, what challenges do Taiwanese EFL learners encounter during translation? Also, what are the learners' perceptions on a flipped translation classroom based on cooperative experiential learning model?

\section{Methods}

\subsection{Participants}

This study was conducted in the English Department of a private comprehensive university in the northern part of Taiwan. Most of the universities in Taiwan offer translation courses not for the purpose of training professional translators, but rather, as part of the curriculum for cultivating the students' English proficiency. The participants of this study were 13 English majors taking a required translation course at their senior year. The participants were about 22 to 23 years old and have studied English as a school subject for at least 12 years. The translation course was a two-hour course which lasted for two semesters. The participants underwent English to Chinese translation in the first semester and Chinese to English translation in the second semester.

\subsection{Instruction Design}

A flipped classroom instruction took place based on cooperative experiential learning model (Figure 1). According to Kolb's (2015) experiential learning model, learning is a continuous cycle which goes from concrete experience, reflective observation, abstract conceptualization, to active participation. Then, the cycle repeats again and again for knowledge transformation to take place. A detailed description of the four stages is as followed.

\section{Stage one: Concrete experience}

The first stage was for the participants to take an active and hands-on approach to learning. Before class, lecture information containing translation techniques and strategies were provided on a learning platform. A text in the source language (English) was provided as homework for participants to translate into Chinese. The participants had to go over the lecture information, translate the text into target language (Chinese), and upload the translation to the learning platform two days before class. By doing the translation on their own, the participants had a concrete experience of translating the text from English to Chinese.

Stage two: Reflective observation

The translations were collected online by the instructor, and then, the instructor broke down the paragraph into sentences, and randomly provided five translations of each source sentence from the participants' homework. When the participants came to class, a document with five sample translations for each sentence was shown to them using the overhead projector, and the participants could view and discuss the sample translations with their peers. This stage involved reflective observation via sharing each other's translation samples. The participants could see different sample translations, reflect upon their own, and discuss with their peers on the appropriateness and accuracy of the sample translations. They could also take advantage of this opportunity to develop deep learning by reflecting on their own translation and comparing with their peers' translations.

\section{Stage three: Abstract conceptualization}

After comparing their own translation with their peers' translations, the participants could form new cognitive concepts on the accuracy and the appropriateness of the translations. Some sample translations were more accurate while others might have deviated more from the source texts. Different sample translations were compared and analyzed according to the use of lexicon, grammatical structures, meaning, and overall fluency. At this stage, new cognitive concepts of better translations were formed. This was also the crucial stage for 
knowledge construction because this was when the internalization of new knowledge takes place.

Stage four: Active experimentation

The final stage was the implementation of new knowledge in future experiences. After discussing with their peers in groups and the internalization of new translation knowledge, the participants were asked to write a revised version of the translation. This revised version of translation was the product of a complex knowledge transformation process which goes from the drafting of the first translation, comparison with sample translations, and internalization of new knowledge. Since the revised translation resulted from cognitive analysis of the strengths and shortcomings of previous translated work via shared knowledge and cooperation, it was usually a better version than the first draft.

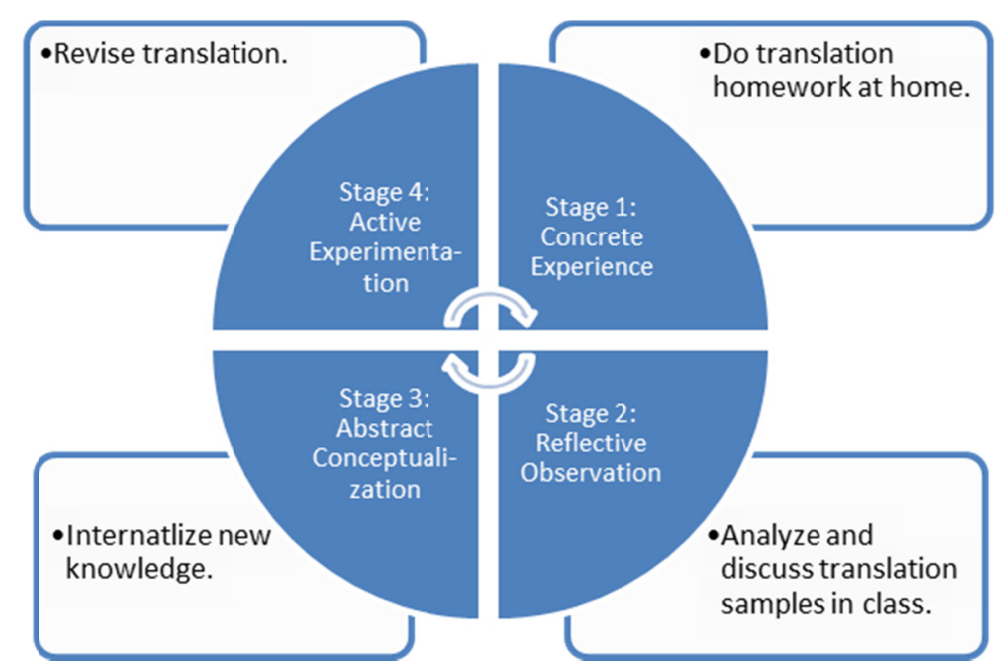

Figure 1. Flipped translation instruction based on cooperative experiential learning

The flipped translation classroom repeated every week and the participants became familiar with this type of instruction.

\subsection{Data Collection and Analyses}

Data were collected from semi-structured interviews with the participants. The interviews had eight prompts and the average time for each interview was about 15 minutes. The prompts asked the participants' perceptions on the process of translation, compared the difference between English - Chinese and Chinese - English translation, and the impacts of collaborative experiential learning in this flipped translation class. The interviews were conducted in the participants' mother tongue to avoid misunderstanding.

The audiotaped interviews were transcribed and later translated into English. Data were analyzed systematically using qualitative conductive approach (Strauss \& Corbin, 1998). The transcribed data were read many times and categorized into meaningful units according to different themes. Personal perceptions and opinions were analyzed to derive at generalizations about the challenges that the participants encountered during translation and their perceptions on the flipped translation instruction based on cooperative experiential learning.

\section{Results and Discussion}

In order to understand the difficulties that the participants encountered when doing translation tasks, and their perceptions on this flipped translation classroom based on cooperative experiential learning, inferences from the participants' interview transcriptions are gathered below.

\subsection{Different Challenges when Translating from L2 to L1 and L1 to L2}

Learners encountered different challenges when translating from L2 to L1 and from L1 to L2. When translating from L2 to L1, the first step is to comprehend the source text in L2. Sometimes, as a non-English native speaker, it is difficult for the learners to understand the meanings behind the $\mathrm{L} 2$ texts. The literal meanings may be easier to comprehend than underlying meanings. However, without a full grasp of English, it is difficult to read between the lines sometimes. 
"It is difficult to think like a native English speaker and understand the meaning completely. So, there is inaccuracy when translating into Chinese." (s1)

"Sometimes I don't fully understand the English text. Sometimes it is the vocabulary and sometimes it is the grammar." (s3)

When the misunderstanding begins with the source text, it leads to more distortions in the translations.

However, when the L2 source text was understood, the learners still have difficulty in translating the text into L1 accurately. Even though the learners were native speakers of Chinese, when carrying out English to Chinese translations, they found it difficult to choose appropriate vocabulary and structures.

"I often translate directly according to the grammatical structures of the L2 source text. Then, the translated text would look very unnatural and awkward, unlike sentences used by native Chinese speakers." (s2)

"Sometimes I don't know the equivalent vocabulary or phrases to use in Chinese." (s5)

Choosing appropriate vocabulary, phrases, and grammatical structures were difficult for majority of the learners because immediately after they read the English source texts, they would be constrained by the source texts, and tended to translate by searching for equivalent correspondences of the words, phrases, and grammatical structures. However, the English and Chinese linguistics systems varied to a great degree, thus, adapting direct translation may pose problems in accuracy and fluency of the translated texts.

Nonetheless, the learners faced different challenges when translating from L1 to L2. When translating from Chinese to English, the understanding of the L1 source texts was not a problem. The problem lied mainly on the learners' English proficiency levels. The learners expressed their concerns on the accurate and fluent use of vocabulary, phrases, sentence structures, and expressions of English.

"Due to differences in thinking and linguistic structures between English and Chinese, the English translations seem unnatural." (s6)

"I can't find appropriate words and phrases. There may be more than one choice in the dictionary and I don't know which one to use." (s7)

"Misuse of vocabulary is a problem. Some words may have the same meaning in Chinese, but they may have other meanings in English." (s11)

Many learners pointed out that "vocabulary", "phrases", and "grammatical structures" prohibited them from producing accurate and fluent English translations. When translating into L2, the grasp of the target language is an important aspect in successful translation. Considering translation from English to Chinese and vice versa, English proficiency levels account for most of the challenges encountered.

\subsection{Active Learning in a Cooperative Experiential Translation Classroom}

A traditional translation class may start with a translation assignment, the students hand in their translated work, the instructor gives a grade, and the students look over their translated work and the grades. Perhaps the instructor may give an overview of the common errors and suggestions for translations. On the other hand, a flipped translation classroom with cooperative experiential learning changes the learning process by shifting the learning responsibility to the learners and engaging learners to take part in active learning.

"It is better to discuss different translations with other students. By comparing different vocabularies, phrases, and others, the impressions are deeply engrained." (s12)

"It is good to have discussion. You can look at others' translations and revise your own translations." (s8)

The learners saw the benefits of having discussions on the sample translations. They felt that comparing and analyzing their peers' translations enabled them to have an insight on the source texts, translated texts, and the revisions.

"I think the discussion is helpful in terms of grammar. Also, I can think of a more precise translation after looking at others' translations." (s13)

"I can have a clearer idea on different word orders and sequences of sentence patterns." (s3)

When the learners looked at different translation samples and underwent discussion, they were able to compile a better translation from the samples. They may not be proficient enough to produce a good translation, but they certainly have the ability to compare and judge translation samples. Thus, after the discussions, they were able to choose appropriate vocabulary and phrases from the samples, and reorganize and formulate sentence patterns for a more accurate and fluent revision. 


\subsection{Elevating the Learning Process from Lower Order Thinking to Higher Order Thinking}

According to Bloom's Taxonomy (1956), adapting higher order thinking skills like analyzing, evaluating, and creating is facilitative in learning. With cooperative experiential learning, learners are able to elevate from lower order thinking skills to higher order thinking skills. When the learners did their translations at home, they looked at the source texts, tried to understand the meanings, and applied their language skills to do the translations.

"Sometimes I just translate word by word, leading to two verbs in one sentence. I didn't know how to change different parts of speech." (s7)

"Because I don't know enough vocabulary and grammatical structures, I always write English sentences that sound like "Taiwanese English"'. (s12)

When working alone, the learners applied what they know about the source and target languages and tried to make translations. That was the reason why word for word equivalents and direct translations were formulated. As a result, awkward sentences that sounded unnatural and somewhat conforming to Chinese linguistic structures were mocked as 'Taiwanese English'. The skills that learners were using were mostly remembering, understanding and applying, considered as lower order thinking skills.

With cooperative experiential learning, the learners started by analyzing, comparing, and evaluating different versions of the translations, and then, reflecting on others' and their own translations. After acquiring the lexicon and grammatical structures of others' translations, the learners internalized the new knowledge and created a revised version. The revised version was an accumulation of others' knowledge, which was often a better version than the one produced earlier.

"From others' sample translations, I can see various combinations." (s5)

"I was able to write better sentences." (s1)

"Through discussion, I can have better translations, something I didn't think of before." (s13)

Majority of the learners agreed that they were more satisfied with the revised translations. This showed that the discussions on sample translations were helpful in triggering different lexicon and grammatical patterns that they couldn't readily recall while doing the translations by themselves. The cooperative learning experience confirms Kolb's experiential learning cycle which goes from concrete experience, reflective observation, abstract conceptualization, and active experimentation, and finally leading to higher order thinking during translation.

\section{Conclusion and Implications}

This research identified the positive effects of cooperative experiential learning in a flipped translation classroom. First of all, cooperative experiential learning helps learners cope with linguistic problems when translating from English to Chinese and vice versa. Second, cooperative experiential learning facilitates active engagement when learners are discussing and comparing translation samples, and elevates the learning process to higher order thinking.

Due to different linguistic systems of Chinese and English, translating from English to Chinese or vice versa requires more than word-for-word direct translation (Nida, 2003). Through cooperative experiential learning, learners share their thoughts on different translation samples, and reconstruct their translations. In this flipped translation classroom, cooperation is part of knowledge construction. By exchanging ideas, thoughts, and translation techniques, learners are able to undergo knowledge construction and move to a deeper understanding of the original text with a better grasp of the target language as well. Better performance on the translation tasks is also expected in a flipped translation classroom utilizing cooperative experiential learning.

Cooperative experiential learning also enables learning engagement through active participation in classroom discussions. Learners are motivated and learning becomes autonomous. Thus, active involvement is another benefit of this flipped translation classroom when compared with traditional translation classrooms. Utilizing higher order thinking activities, like discussion and analyses, is effective in cultivating translation skills and overall language proficiency.

The findings of this research provide pedagogical contribution in suggesting a learner-centered method in teaching translation. Higher order thinking in a flipped classroom is made possible through cooperative experiential learning and learners are able to construct and internalize translation knowledge via lively discussions. However, there are still some limitations in this research. The lacking of a control group limits extended inferences on the significant impacts of this flipped translation classroom because there is no comparison with that of traditional teacher-centered translation classrooms. Also, the effects of cooperative experiential learning cannot be verified without quantitative data. Hence, it is suggested that future research 
includes a control group and makes good use of quantitative analysis. The findings can also provide research implications for relevant studies on different translation teaching and learning methods.

\section{Acknowledgments}

This research was supported by Taiwan's Ministry of Science and Technology (MOST107-2635-H-032-003).

\section{References}

Anderson, L. W., \& Krathwohl, D. R. (2001). A taxonomy for learning, teaching, and assessing: A revision of Bloom's taxonomy of educational objectives. New York, NY: Longman.

Bergmann, J., \& Sams, A. (2012). Flip your classroom: Reach every student in every class every day. International Society for Technology in Education.

Berrett, D. (2012). How 'flipping' the classroom can improve the traditional lecture. The Education Digest, 78(1), 36.

Bishop, J. L., \& Verleger, M. A. (2013, June). The flipped classroom: A survey of the research. In ASEE National Conference Proceedings, Atlanta, GA (Vol. 30, No. 9, pp. 1-18).

Bloom, B. S., Englehart, M. D., Furst, E. J., Hill, W. H., \& Krathwohl, D. R. (1956). Taxonomy of educational objectives. Handbook 1: Cognitive domain. New York, NY: Longmans.

Calvo, E. (2015). Scaffolding translation skills through situated training approaches: Progressive and reflective methods. The Interpreter and Translator Trainer, 9(3), 306-322. https://doi.org/10.1080/1750399X.2015.1103107

Colina, S. (2002). Second language acquisition, language teaching and translation studies. The Translator, 8(1), 1-14. https://doi.org/10.1080/13556509.2002.10799114

Corbin, J., \& Strauss, A. (2008). Basics of qualitative research: Techniques and procedures for developing grounded theory (3rd ed.). Thousand Oaks, CA: Sage. https://doi.org/10.4135/9781452230153

Davies, M. G. (2005). Minding the process, improving the product: Alternatives to traditional translator training. In M. Tennent (Ed.). Training for the new millennium (pp. 67-82). Philadelphia, PA: John Benjamins Publishing Co. https://doi.org/10.1075/btl.60.09gon

Dewey, J. (1938). Experience and education. New York, NY: Macmillan.

Hung, H. T. (2015). Flipping the classroom for English language learners to foster active learning. Computer Assisted Language Learning, 28(1), 81-96. https://doi.org/10.1080/09588221.2014.967701

King, A. (1993). From sage on the stage to guide on the side. College Teaching, 41(1), 30-35. https://doi.org/10.1080/87567555.1993.9926781

Kiraly, D. C. (1995). Pathways to translation: Pedagogy and process. Kent, OH: The Kent State University Press.

Kiraly, D. C. (2000). A social constructivist approach to translator education. Manchester, UK: St. Jerome.

Kiraly, D. (2014). A social constructivist approach to translator education: Empowerment from theory to practice. Routledge. https://doi.org/10.4324/9781315760186

Kohonen, V. (1992). Experiential language learning: second language learning as cooperative learner education. In D. Nunan (Ed.), Collaborative language learning and teaching (pp. 14-39). Cambridge, UK: Cambridge University Press.

Kolb, D. A. (2015). Experiential learning.: Experience as the source of learning and development (2nd ed.). Upper Saddle River, NJ: Pearson Education, Inc.

Lage, M. J., Platt, G. J., \& Treglia, M. (2000). Inverting the classroom: A gateway to creating an inclusive learning environment. The Journal of Economic Education, 31(1), 30-43. https://doi.org/10.2307/1183338

Liao, P. (2009). The implications and implementation of communicative translation teaching. Compilation and Translation Review, 2(2), 65-91.

Motta, M. (2016). A blended learning environment based on the principles of deliberate practice for the acquisition of interpreting skills. The Interpreter and Translator Trainer, 10(1), 133-149. https://doi.org/10.4324/9780203732304-9

Nida, E. A., \& Taber, C. R. (2003). The theory and practice of translation (Vol. 8). Brill. 
Prince, M. (2004). Does active learning work? A review of the research. Journal of Engineering Education, 93(3), 223-231. https://doi.org/10.1002/j.2168-9830.2004.tb00809.x

Roehl, A., Reddy, S. L., \& Shannon, G. J. (2013). The flipped classroom: An opportunity to engage millennial students through active learning. Journal of Family and Consumer Sciences, 105(2), 44. https://doi.org/10.14307/JFCS105.2.12

Shreve, G. M. (2006). The deliberate practice: Translation and expertise. Journal of Translation Studies, 9(1), $27-42$.

Tucker, B. (2012). The flipped classroom. Education Next, 12(1), 82-83.

Zhong, Y. (2008). Teaching translators through self-directed learning. The Interpreter and Translator Trainer, 2(2), 203-220. https://doi.org/10.1080/1750399x.2008.10798774

\section{Copyrights}

Copyright for this article is retained by the author, with first publication rights granted to the journal.

This is an open-access article distributed under the terms and conditions of the Creative Commons Attribution license (http://creativecommons.org/licenses/by/4.0/). 